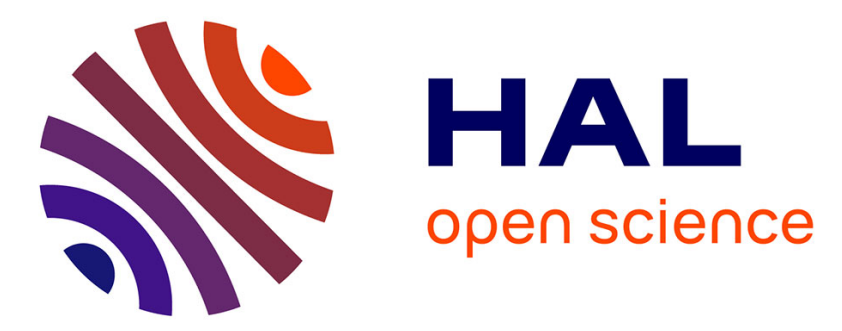

\title{
Design and magnetic noise reduction of the Surface Permanent Magnet Synchronous Machine using complex airgap permeance
}

Mathias Fakam, Michel Hecquet, Vincent Lanfranchi, Andry Randria

\section{- To cite this version:}

Mathias Fakam, Michel Hecquet, Vincent Lanfranchi, Andry Randria. Design and magnetic noise reduction of the Surface Permanent Magnet Synchronous Machine using complex airgap permeance. IEEE Transactions on Magnetics, 2015, 51 (4), pp.8103809. 10.1109/TMAG.2014.2360315 . hal01711078

\section{HAL Id: hal-01711078 \\ https://hal.science/hal-01711078}

Submitted on 16 Feb 2018

HAL is a multi-disciplinary open access archive for the deposit and dissemination of scientific research documents, whether they are published or not. The documents may come from teaching and research institutions in France or abroad, or from public or private research centers.
L'archive ouverte pluridisciplinaire HAL, est destinée au dépôt et à la diffusion de documents scientifiques de niveau recherche, publiés ou non, émanant des établissements d'enseignement et de recherche français ou étrangers, des laboratoires publics ou privés. 


\title{
Design and magnetic noise reduction of the Surface Permanent Magnet Synchronous Machine using complex airgap permeance.
}

\author{
Mathias Fakam ${ }^{1}$, Michel Hecquet ${ }^{1}$, Vincent Lanfranchi ${ }^{2}$, and Andry Randria ${ }^{3}$ \\ ${ }^{1}$ L2EP - Ecole Centrale de Lille, Cité scientifique, 59651 Villeneuve d'Ascq, France \\ ${ }^{2}$ LEC - UTC, BP 20529, 60205 Compiègne Cedex, France \\ ${ }^{3}$ ALSTOM Transport, 7 Avenue Mal de Lattre de Tassigny, 25290 Ornans, France
}

\begin{abstract}
Nowadays, the development of the electric motorization for land vehicles is essential since the energetic challenge has become very critical. This paper presents the development of a tool used for the optimal acoustic and electromechanical modeling which stands out from standard analytical and Finite Element modeling respectively, due to the high accuracy of calculations and the quickness of the resolution. Thanks to a coupling between an analytical model and statics FE simulations, a complex global air-gap permeance per area unit is calculated by our 'hybrid' model, in order to take into account the permeability of magnetic wedges, the height of pre-slots, and the rotor shape. An unequalled level of precision and speed of resolution is obtained for the computation of air-gap magnetic pressures. Some results of comparison between acoustic measurement and simulation on a concentrated winding motor, for different speeds, will be presented.
\end{abstract}

Index Terms-Magnetic noise, vibrations, Maxwell pressures, airgap permeance, pulsewidth modulation, distributed and concentrated windings, permanent magnets.

\section{INTRODUCTION}

$\mathbf{N}$ OWADAYS, the development of the electric motorization for land vehicles is essential, since the energetic challenge has become very critical. Electrical machines dedicated to this operating segment have some particularities of torque characteristics (high saturation level, important flux weakening) over the speed range. In addition, an acoustic comfort becomes increasingly important in electric transportation systems as subways, trains but also electrical vehicles. Traction motors are more and more submitted to severe environmental requirements, among which the restrictive standards of noise level. Our idea is to develop a multi-physics model in order to design and predict the electromagnetic noise produced by permanent magnet (PM) synchronous motors equipped with concentrated windings (CW), and fed by a pulsewidth modulation (PWM) converter.

For that purpose, three main steps are required. The first step consists in the computation of the air-gap magnetic pressure thanks to a magnetic model. The second part is the mechanical model, which characterizes the vibrating structure and calculates the vibratory reponse from the structure to airgap magnetic pressure requests. Finally, the last part of the model represents the transfer function of the vibratory energy into acoustic energy. This modeling can be fully numerical, semi-analytical or fully analytical.

In spite of the good precision of fully numerical modeling [1] [2] [3], this approach, for the design tool, is not convenient because it is very expensive at calculation time. Lumped models, which are less accurate than the numerical models, are relatively fast [4] [5]. However, for CW configuration especially, the spatial discretization must be important to determine precisely the air-gap magnetic pressure distribution and computing time grows exponentially. Only analytical modeling allows to design, and also to optimize structures with the aim to minimize the magnetic noise radiated by an electrical motor, fed by a PWM converter with a variable speed [10].

A 2D sub-domain method [6], [8] and [9] can be used to determine with good accuracy the analytical magnetic field in the air-gap, tangential and radial components. Unfortunately, many assumptions exist: linear case, slotless machine or slotted machine at no-load configuration. To overcome these limitations, a 'hybrid' model is developed with analytical and finite element (FE) modeling. In this paper, the fast computing time of analytical models will be associated to the high accuracy of the FE simulations, in order to compute tangential and radial components of the air-gap magnetic field in a slotted machine fed by a PWM converter with a variable speed.

For the magnetic part, which is the topic of this study, a numerical - analytical coupling is set up to calculate the airgap magnetic pressures. Global air-gap permeance per area unit is calculated thanks to statics FE simulations, in order to take into account the wedge permeability and the rotor shape. To demonstrate the originality of our 'hybrid' model, the results were compared with the results obtained to a fully analytical model [14] [7], for total air-gap permeance computations. An unequalled level of precision and speed of resolution is obtained for the computation of air-gap magnetic pressures.

Concerning the vibro acoustic modeling, the analytical mechanical model described by [11] has been successfully experimented. Dynamic deflections, which account for resonance effects and the sound power radiated by vibrations of mode $m$ at the frequency $f$ can be calculated according to [12]. A similar case of a surface PM motor using this vibro-acoustic analytical modeling was already published [4].

The quickness of the resolution allows coupling our tool with an optimization supervisor. One prototype was designed and built in order to validate the multi-physics model. The 
prototype is a $1.5 \mathrm{~kW}$ motor equipped wih a $\mathrm{CW}$ stator and a surface PM rotor (CW-SPM).

\section{Electromagnetic MODELING}

The electromagnetic model calculates radial Maxwell's magnetic pressures on the average air-gap. These pressures express as follows:

$$
p_{e}(\alpha, t)=\frac{1}{2 \mu_{0}}\left[B_{e_{r}}^{2}(\alpha, t)-B_{e_{\theta}}^{2}(\alpha, t)\right]
$$

$B_{e_{r}}$ and $B_{e_{\theta}}$ stand respectively for radial and tangential components of air-gap magnetic flux density. $\alpha$ is the spatial air-gap discretization, and $t$ is the time discretization. The total air-gap flux density, $B_{e}$, is the product between the conjugate of the air-gap permeance $\Lambda(\alpha, t)$ and the sum of magnetomotive forces developed by the stator winding $f_{m m}^{s}(\alpha, t)$, and PM rotor $f_{m m}^{r}(\alpha, t)$. It could be expressed:

$$
\begin{aligned}
B_{e}(\alpha, t) & =B_{e_{r}}+j B_{e_{\theta}} \\
& =\left[\Lambda_{r}(\alpha, t)+j \Lambda_{\theta}(\alpha, t)\right]^{*} \times \sum_{i=r, s} f_{m m}^{i}(\alpha, t)
\end{aligned}
$$

$\Lambda_{r}$ and $\Lambda_{\theta}$ stand respectively for radial and tangential components of air-gap permeance per area unit. The magnetomotrices forces are also expressed as complex equation. With this formulation, it's possible to apply all mathematical operations to a single variable, grouping two data.

\section{A. Complex air-gap permeance}

A numerical - analytical coupling is set up to calculate the airgap permeance per area unit. In the state of art of the modelling, it's undoubtedly the most precise method to compute the airgap permeance. In the literature, several analytical modelling are proposed [14]. Our method provides better results if the wedge permeability, the rotor shape and the asymmetry of stator teeth owe beings considerations. The procedure consists in the estimation of fluctuations in the air-gap magnetic field, introduced respectively by stator teeth and rotor PM. There are none major assumptions (rectangular stator teeth or cylindrical rotor shape).

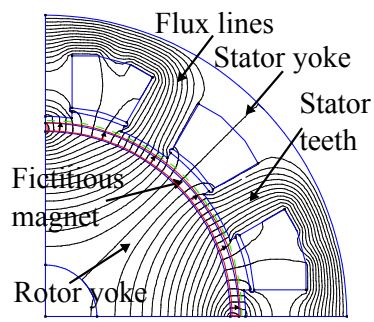

(a) Slotted stator EF simulation

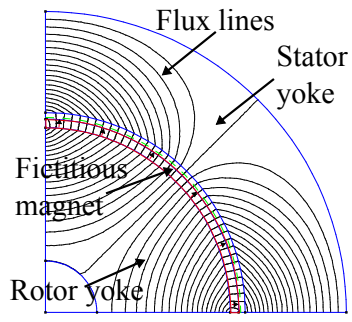

(b) Slotless stator EF simulation
Fig. 1: EF simulations: air-gap permeance of a $\mathrm{CW}$ stator.

To determine the fluctuations in the average air-gap magnetic field caused by the set of teeth of the stator and rotor shape, two series of two magnetostatics finite elements simulations are necessary (Figs. 1a and 1b). A fictitious magnet allows to impose a constant magnetomotive force, $f_{m f_{r}}$, on all nodes of the average mechanical air-gap radius $R_{\text {avg }}$. The fictitious magnet has magnetic properties of rare-earth, and imposes a magnetomotive force which is determined by the simulation without stator teeth.

With simulations in Fig. 1b, radial $\left(H_{r}\right)$ and tangential $\left(H_{\theta}\right)$ components of the air-gap magnetic field are recorded. $h_{m f}$ is the fictitious magnet thickness. It comes:

$$
\begin{aligned}
& f_{m f_{r}}(\alpha)=h_{m f} H_{r}(\alpha) \\
& f_{m f_{\theta}}(\alpha)=\Delta \alpha R_{a v g} H_{\theta}(\alpha)
\end{aligned}
$$

With simulations illustrated in Figs. 1a, radial $\left(B_{r}\right)$ and tangential $\left(B_{\theta}\right)$ components of the air-gap magnetic flux density are recorded. The air-gap permeance per area unit is a physical quantity which results from variations of magnetic resistances of flux tubes in the average air-gap. A good estimation of the global air-gap permeance per unit is obtained by applying the equality of the real (radial) and imaginary (tangential) parts as follows [7]:

$$
\begin{aligned}
& \Lambda_{r}(\alpha)=\frac{B_{r}(\alpha) f_{m f_{r}}(\alpha)+B_{\theta}(\alpha) f_{m f_{\theta}}(\alpha)}{f_{m f_{r}}^{2}(\alpha)+f_{m f_{\theta}}^{2}(\alpha)} \\
& \Lambda_{\theta}(\alpha)=\frac{B_{r}(\alpha) f_{m f_{\theta}}(\alpha)-B_{\theta}(\alpha) f_{m f_{r}}(\alpha)}{f_{m f_{r}}^{2}(\alpha)+f_{m f_{\theta}}^{2}(\alpha)}
\end{aligned}
$$

$\Lambda_{r}$ and $\Lambda_{\theta}$ stand respectively for radial and tangential components of air-gap permeance per area unit. It is thanks to Eqs. 5 and 6 that air-gap permeances are calculated.

The same technique is applied to consider the variations of air-gap permeance introduced by the rotor shape. The first (Fig. 2a) simulation allows to record magnetic flux density components $\left(B_{r}\right.$ and $\left.B_{\theta}\right)$. The second simulation allows to find magnetomotive force components in the average air-gap $\left(f_{m f_{r}}\right.$ and $\left.f_{m f_{\theta}}\right)$ set by the fictitious magnet.

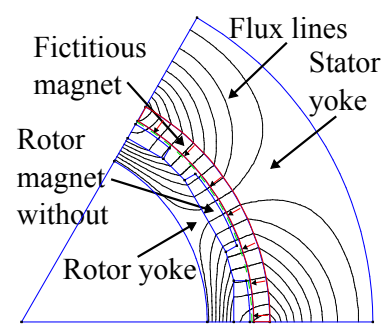

(a) With inactive rotor magnets

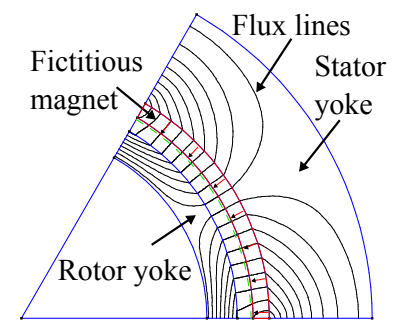

(b) Without rotor magnets
Fig. 2: EF simulations: air-gap permeance of a mounted surface PM rotor.

By analyzing the curves of the Fig. 3, radial and tangential components of the air-gap permeance expressed by equations above, introduced by stator teeth, can also be written in the form of Fourier series as follow, where $Z_{s}$ stands for the stator teeth number, and $k_{s}$ an integer).

$$
\begin{aligned}
& \Lambda_{s_{r}}(\alpha)=\Lambda_{s}^{0}+\sum_{k_{s}=1}^{\infty} \Lambda_{k_{s r}}^{s} \cos \left(k_{s} Z_{s} \alpha\right) \\
& \Lambda_{s_{\theta}}(\alpha)=\sum_{k_{s}=1}^{\infty} \Lambda_{k_{s \theta}}^{s} \sin \left(k_{s} Z_{s} \alpha\right)
\end{aligned}
$$

Also, radial and tangential components of the air-gap permeance expressed by Eqs. 5 and 6, introduced by rotor shape 
can be written as show by Equations below, where $p$ stands for the pole pair number, $\omega$ the synchronous frequency, and $k_{r}$ an interger.

$$
\begin{aligned}
& \Lambda_{r_{r}}(\alpha, t)=\Lambda_{r}^{0}+\sum_{k_{r}=1}^{\infty} \Lambda_{k_{r r}}^{r} \cos \left(k_{r} 2 p \alpha+k_{r} 2 \omega t\right) \\
& \Lambda_{r_{\theta}}(\alpha, t)=\sum_{k_{r}=1}^{\infty} \Lambda_{k_{r \theta}}^{r} \sin \left(k_{r} 2 p \alpha+k_{r} 2 \omega t\right)
\end{aligned}
$$

The expression of the total air-gap permeance components are obtained having to identify Fourier coefficients $\Lambda_{s}^{0}, \Lambda_{k_{s r}}^{s}$, $\Lambda_{k_{s \theta}}^{s}, \Lambda_{r}^{0}, \Lambda_{k_{r r}}^{r}, \Lambda_{k_{r \theta}}^{r}$. In our model, it's expressed under complex form as follows:

$$
\Lambda(\alpha, t)=\Lambda_{r}(\alpha, t)+j \Lambda_{\theta}(\alpha, t)
$$

where

$$
\begin{aligned}
\Lambda_{r}(\alpha, t) \approx & 2 \frac{\Lambda_{s}^{0} \Lambda_{r}^{0}}{\Lambda_{s}^{0}+\Lambda_{r}^{0}}+\sum_{k_{s}=1}^{\infty} \Lambda_{k_{s r}}^{s} \cos \left(k_{s} Z_{s} \alpha\right) \\
& +\sum_{k_{r}=1}^{\infty} \Lambda_{k_{r r}}^{r} \cos \left(k_{r} 2 p \alpha+k_{r} 2 \omega t\right) \\
\Lambda_{\theta}(\alpha, t) \approx & \sum_{k_{s}=1}^{\infty} \Lambda_{k_{s \theta}}^{s} \sin \left(k_{s} Z_{s} \alpha\right) \\
& +\sum_{k_{r}=1}^{\infty} \Lambda_{k_{r \theta}}^{r} \sin \left(k_{r} 2 p \alpha+k_{r} 2 \omega t\right)
\end{aligned}
$$

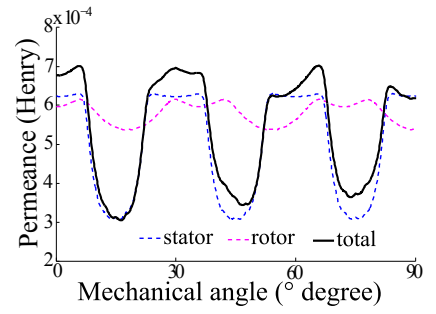

(a) $\mathrm{CW}$ radial component.

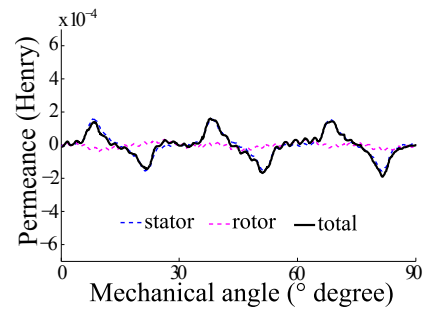

(b) $\mathrm{CW}$ tangential component.
Fig. 3: Radial and tangential components of the air-gap permeance variations, introduced by the rotor shape, stator teeth, PM and wedges permeability.

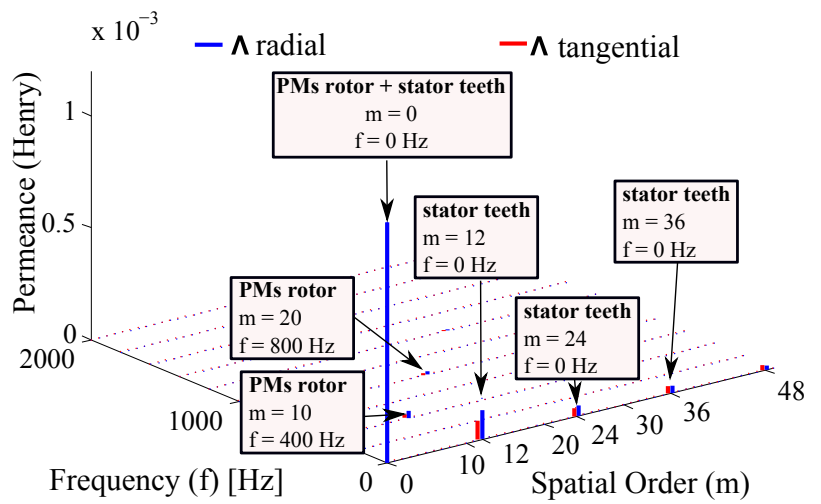

Fig. 4: Time-space harmonics of radial and tangential components the air-gap permeance variations at $f_{s}=200 \mathrm{~Hz}$, introduced by the rotor shape and stator teeth.

The Fig. 3 shows the spatial distribution of the air-gap permeance at the given time. To take into account the movement, the fluctuations in permeance introduced by the rotor are going to be moved by an angle $\theta_{\text {step }}=\Omega_{s} t_{\text {step }}$, where $\Omega_{s}$ is the angular synchrounous speed and $t_{\text {step }}$ the time steps of calculation. We obtain then the time-space spectrum of the airgap permeance, presented in Fig. 4. The Table I recapitulates time-space harmonics of the total air-gap permeance per area unit. In this table, harmonic contents from interaction between stator air-gap permeance contributions and rotor airgap permeance contributions, are not taken into account.

TABLE I: Air-gap permeance per area unit; time-space harmonic contents.

\begin{tabular}{|c|c|c|}
\hline Harmonics & Spatial order $(m)$ & Frequency $(f) \mathrm{Hz}$ \\
\hline \hline $\boldsymbol{\Lambda}_{\mathbf{0}}^{m, f}$ & 0 & 0 \\
\hline $\boldsymbol{\Lambda}_{\mathbf{k}_{\mathbf{s}}, f}^{m, f}$ & $k_{s} Z_{s}$ & 0 \\
\hline $\boldsymbol{\Lambda}_{\mathbf{k}_{\mathbf{r}}}^{m, f}$ & $2 k_{r} p$ & $2 k_{r} f_{s}$ \\
\hline
\end{tabular}

Indeed, these contributions can be neglected for mounted surface PM rotor. Furthermore, harmonic contents from saturation effect, are not either taken into account. With the numerical coupling realized in our modelling, effect of saturation due to PM are already taken into account. The insertion of PM in rotor laminations does not change, qualitatively, the harmonic contents of the air-gap permeance [13].

\section{B. Stator winding magnetomotive forces}

The expression of magnetomotive forces developed by the stator winding in the air-gap, $f_{m m}^{s}(\alpha, t)$, is given by [15]:

$$
f_{m m}^{s}(\alpha, t)=\sum_{q=1}^{q_{s}} N_{q}^{s}(\alpha) i_{q}^{s}(t)
$$

where $q_{s}$ is the number of stator phases. $N_{q}^{s}(\alpha)$ is the winding distribution function associated to the $q^{t h}$ stator phase, and $i_{q}^{s}(t)$ represents the current flowing in the same stator phase. These currents are obtained by using an extension of the fundamental single-phase equivalent circuit [16], applied to a permanent magnet synchronous motor (Eq. 15); $i_{q}^{s}(t)=$ $\mathrm{TFD}^{-1}\left\{I_{s}^{n}\right\}$. Each time harmonic $U^{n}$, of frequency $f_{n}^{s}$, comes from the PWM supply phase voltage.

$$
U^{n}=\left(R_{s}^{n}+j X_{s}^{n}\right) I_{s}^{n}+E^{n}
$$

The calculations of the resistances $R_{s}$, and the synchronous reactances $X_{s}$ are not discussed on this paper. $E^{n}=$ TFD $\{e(t)\}$, where $e(t)$ is the back electromotive force (Back EMF). The Back EMF is calculated by using the Eq. 2 without stator winding magnetomotive forces. The Back EMF is thus the coupling variable between the electric model (Eq. 15) and the magnetic model (Eq. 2).

TABLE II: Stator winding magnetomotive forces; time-space harmonic contents.

\begin{tabular}{|c|c|c|}
\hline Harmonics & Spatial order $(m)$ & Frequency $(f) H z$ \\
\hline \hline $\mathbf{F}_{\mathbf{s}}^{m, f}$ & $\nu p$ & $f_{n}^{s}$ \\
\hline
\end{tabular}

By considering PWM supply voltage, harmonic contents of stator winding magnetomotive forces are recapitulated in the Table II. $k_{s}=0, \pm 1, \pm 2, \ldots$ Notice that the expression of $\nu$, in the Table II, depends on the winding type: 
- $\nu=\left(2 q_{s} k_{s}+1\right)$ for a Distrituted Winding (DW) with an interger winding pitch;

- $\nu=\left(q_{s} k_{s}+1\right)$ for a DW with an fractional winding pitch;

- $\nu=\left(2 q_{s} k_{s}+1\right) / p$ for a CW.

Futhermore, the expression of $f_{n}^{s}$, in the Table II, depends on the voltage supply. With $f_{s}$ and $f_{c}$ stand respectivetly for the synchronous frequency and the carrier frequency of the PWM converter, $n_{1}$ et $n_{2}$ integers of opposite parity and $n=$ $0, \pm 1, \pm 2, \ldots$, it comes:

- $f_{n}^{s}=f_{s}$ for sine waves voltage supply;

- $f_{n}^{s}=n_{1} f_{s} \pm n_{2} f_{c}$ for synchronous and asynchrounous intersective PWM;

- $f_{n}^{s}=(2 n+1) f_{s}$ for calculated angles and full wave modulations.

\section{PM magnetomotive forces}

For the calculation of magnetomotive forces developed by PM in the average air-gap, $f_{m m}^{r}(\alpha, t)$, a very accurate method, the $2 \mathrm{D}$ resolution of Laplacian / quasi-Poisson equations, is going to be used. Following main assumptions are going to be made: a slotless stator and an infinitely permeability of the iron.

Articles [6] and [8] present an exhaustive and complete work of air-gap magnetic field calculations for an unslotted stator, and thus PM magnetomotive forces. The only modification made here will be the consideration of the breadloaf shape of PM.

Time-space harmonics of magnetomotive forces developed by PM are recapitulated in the Table III, where $\mu=\left(2 k_{r}+1\right)$, with $k_{r}=0,1,2,3, \ldots$

TABLE III: PM magnetomotive forces; time-space harmonic contents.

\begin{tabular}{|c|c|c|}
\hline Harmonics & Spatial order $(m)$ & Frequency $(f) \mathrm{Hz}$ \\
\hline \hline $\mathbf{F}_{\mathbf{r}}^{m, f}$ & $\mu p$ & $\mu f_{s}$ \\
\hline
\end{tabular}

\section{Air-gap magnetic flux density}

Radial and tangential components of the air-gap magnetic flux density are calculated by applying the Eq. 2. For a 12 slots/10 poles motor (CWSPM-12s10p), some results of the 'hybrid' model will be compared with the purely numerical simulations (Figs. 5).

The harmonic content of the radial component is presented in the Fig. 5a, whereas that of the tangential component are illustrated by the Fig. 5b. The harmonic content (frequencies) of both components of the air-gap flux density are identical. There is a very good match between the results of numerical simulations and the results of our 'hybrid' model.

The resolution of both models (numerical and hybrid) is parametrized on 256 time steps of calculation. With the numerical tool (Flux2D), the solution is obtained in 120 seconds. With the hybrid modelling, it is made in 24 seconds. It is thus possible to have a significant reduction of the computing time, while guaranteeing a very good accuracy.

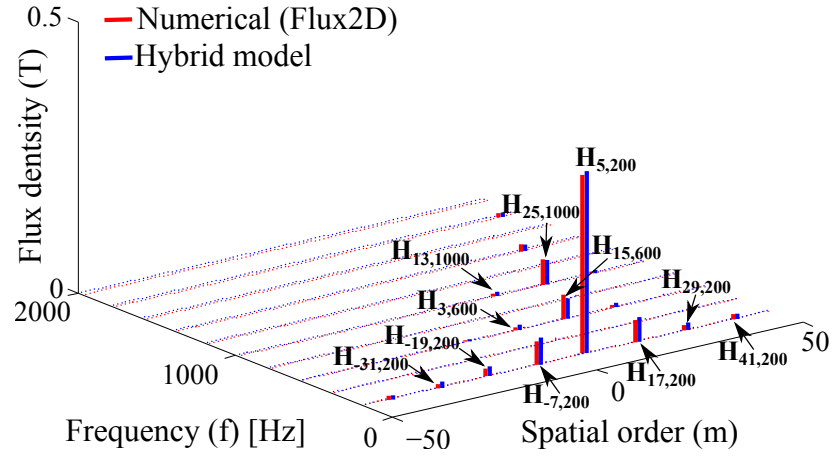

(a) Radial air-gap flux density.

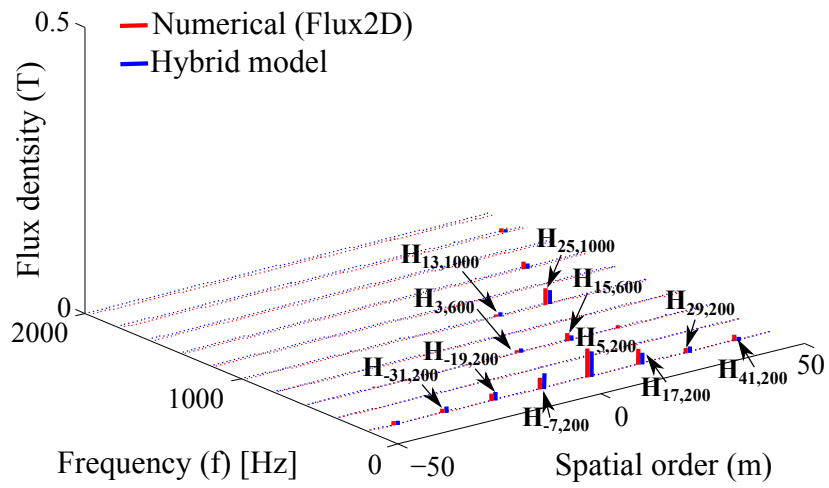

(b) Tangential air-gap flux density.

Fig. 5: Comparison of time-space harmonics $H_{m, f}$ between 'hybrid' model and fully numerical model (Flux2D) at $f_{s}=$ $200 \mathrm{~Hz}$. No load CWSPM-12s10p air-gap flux density components.

The hybrid model was set up to calculate exactly and quickly the air-gap flux density. It can not only handle classic parameters such as the number of rotor poles, the number of stator teeth, the tooth pitch step, the pole pitch, the opening and the thickness of the PM, the slot opening and stator teeth width, but also supplementary parameters such as the relative permeability of magnetic wedges, PM shape, and the height of pre-slots.

To demonstrate the robustness of the hybrid model, studies of sensibility on the main sizing variables, especially the opening and the thickness of the PM $\beta_{m}$, the relative permeability of magnetic wedges $\mu_{\text {wed }}$, and the height of pre-slots with magnetic wedges $h_{i t h s}$, were made.

In Figs. $6 \mathrm{a}$ and $6 \mathrm{~b}$, the thickness of the PM is adjusted to keep the PM mass $M_{m}$ unchanging. These figures compare radial and tangential components of the air-gap flux density from numerical simulations and from the hybrid model. The opening of the PM varies from $\beta_{m}=0.555$ to $\beta_{m}=0.833$. The results of both models present a good agreement.

In Figs. $6 \mathrm{c}$ and $6 \mathrm{c}$, the relative permeability of magnetic wedges varies from $\mu_{\text {wed }}=1$ to $\mu_{\text {wed }}=10$. This parameter of sizing is used to reduce harmonics contents of the air-gap density flux, with the aim of minimizing the magnetic losses in $\mathrm{PM}$, and reducing the cogging torque and the magnetic noise. The results of both models present a good correspondance.

Finally, in Figs. 6e and 6f, the relative permeability of magnetic wedges is $\mu_{w e d}=10$ and the height of pre-slots 
varies from $h_{i t h s}=0.5 \mathrm{~mm}$ to $h_{i t h s}=5 \mathrm{~mm}$. This parameter of sizing is used to keep away the winding of the air-gap zone and of its magnetic exchanges, to reduce magnetic losses in the stator copper. The results of the hybrid model are very satisfactory.

Thanks to this modelling, and with the aim of minimizing the losses due to magnetic fields in the air-gap, it is thus possible to find quickly the good compromise between the permeability of magnetic wedges and the height of pre-slots.

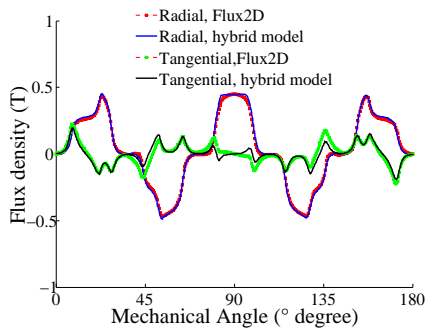

(a) $\beta_{m}=0.555, M_{m}=0.37 \mathrm{~kg}$.

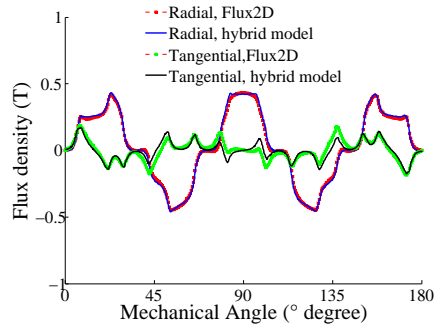

(c) $\mu_{\text {wed }}=1, h_{\text {iths }}=1 \mathrm{~mm}$.

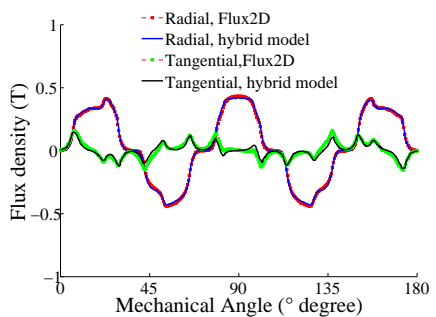

(e) $h_{\text {iths }}=0.5 \mathrm{~mm}, \mu_{\text {wed }}=10$.

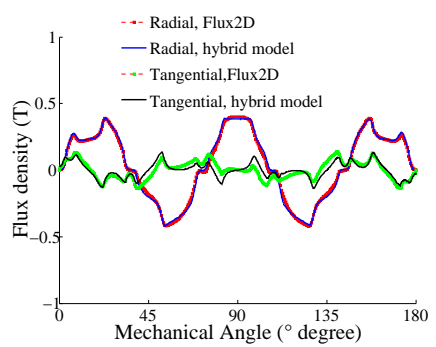

(b) $\beta_{m}=0.833, M_{m}=0.37 \mathrm{~kg}$.

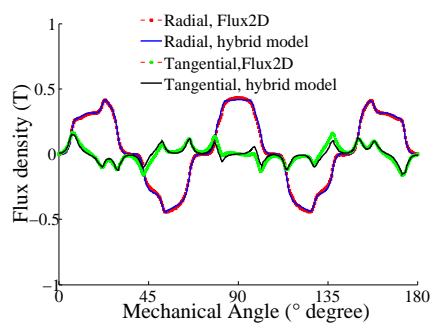

(d) $\mu_{\text {wed }}=10, h_{i t h s}=1 \mathrm{~mm}$.

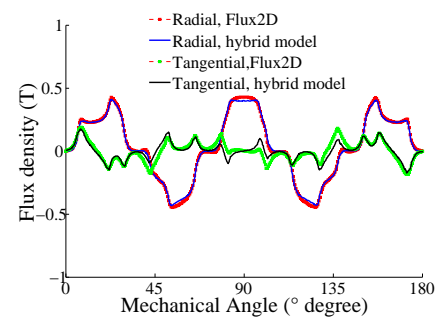

(f) $h_{i t h s}=5 \mathrm{~mm}, \mu_{w e d}=10$.
Fig. 6: Sensitivity studies and comparison between 'hybrid' model and fully numerical model (Flux2D). Air-gap flux density components.

\section{E. Radial air-gap magnetic pressure}

Radial components of the Maxwell's air-gap magnatic presssure are calculated by applying the Eqs 1 . To validate the calculation of these magnetic pressures by our model, two simultaions were realized.

The first simulation (SimA) is a point where the magnetic torque is maximum. So, there are a angle of 90 degree between magnetic fields developed respectively by the winding and the PM. Figs. 7a and 7b show and compare spatial distributions and their harmonics content of the Maxwell's air-gap magnatic presssure. The numerical simulation was realized at $t=0$ second. In this configuration, $i_{1}=-2.676 \mathrm{~A}, i_{2}=19.317 \mathrm{~A}$ and $i_{3}=-16.641 \mathrm{~A}$.

The second simulation ( $\operatorname{SimB})$ is a point with flux weakening. Figs. $7 \mathrm{c}$ and $7 \mathrm{~d}$ show and compare spatial distributions and their harmonics content of the Maxwell's air-gap magnetic presssure. The numerical simulation was realized at $t=0$ second. In this configuration, $i_{1}=-3.02 \mathrm{~A}, i_{2}=4.23 \mathrm{~A}$ and $i_{3}=1.21 \mathrm{~A}$. Notice that, in the two simulations (SimA and SimB), there are a good match between both models, especially their harmonics content.

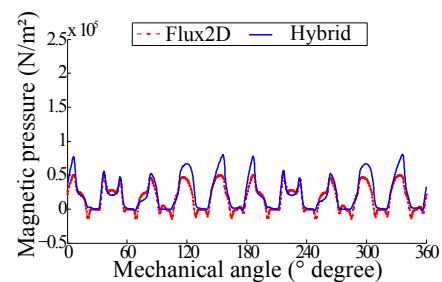

(a) SimA: $p_{e}(\alpha, t=0)$.

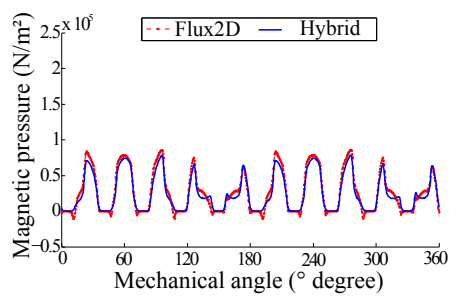

(c) SimB: $p_{e}(\alpha, t=0)$.

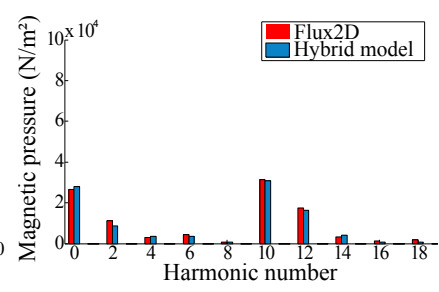

(b) SimA: TFD $\left\{p_{e}(\alpha, t=0)\right\}$.

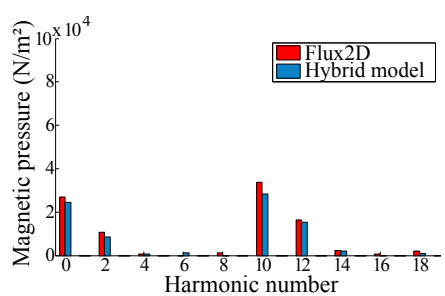

(d) SimB: TFD $\left\{p_{e}(\alpha, t=0)\right\}$.
Fig. 7: Comparison between 'hybrid' model and fully numerical model (Flux2D). Radial components of the Maxwell's air-gap magnatic presssure. Loaded motor.

To analyze the time-space harmonics content of the Maxwell's air-gap magnetic presssure, it is necessary to introduce a frequency formalism. So, harmonic contents given in Tables I, II and III can be to written as follows:

$$
\begin{aligned}
\mathbf{F}_{\mathbf{s}}{ }^{m_{s}, f_{s}} & =\mathbf{F}_{\mathbf{s}}{ }^{\nu p, f_{n}^{s}} \\
\mathbf{F}_{\mathbf{r}}{ }^{m_{r}, f_{r}} & =\mathbf{F}_{\mathbf{r}}{ }^{\mu p, \mu f_{s}} \\
\boldsymbol{\Lambda}^{m_{\Lambda}, f_{\Lambda}} & =\boldsymbol{\Lambda}_{0}+\boldsymbol{\Lambda}_{\mathbf{k}_{\mathbf{s}}}{ }^{k Z_{s}, 0}+\boldsymbol{\Lambda}_{\mathbf{k}_{\mathbf{r}}}{ }^{2 k p, 2 k f_{s}}
\end{aligned}
$$

Harmonic contents of the Maxwell's air-gap magnetic pressure are determined thanks to the following equation:

$$
\begin{aligned}
\mathbf{P}^{m, f}= & \frac{1}{2 \mu_{0}}\left[\boldsymbol{\Lambda}^{m_{\Lambda}, f_{\Lambda}}\left(\mathbf{F}_{\mathbf{r}}{ }^{m_{r}, f_{r}}+\mathbf{F}_{\mathbf{s}}{ }^{m_{s}, f_{s}}\right)\right]^{2} \\
= & \overbrace{\frac{1}{2 \mu_{0}}\left(\boldsymbol{\Lambda}^{m_{\Lambda}, f_{\Lambda}}\right)^{2} \times\left(\mathbf{F}_{\mathbf{r}}^{m_{r}, f_{r}}\right)^{2}}^{\text {Family 1: Air-gap permeance + PM }} \\
& +\overbrace{\frac{1}{2 \mu_{0}}\left(\boldsymbol{\Lambda}^{m_{\Lambda}, f_{\Lambda}}\right)^{2} \times\left(\mathbf{F}_{\mathbf{s}}^{m_{s}, f_{s}}\right)^{2}}^{\text {Family 2: Air-gap permeance + Winding }} \\
& +\overbrace{\frac{1}{\mu_{0}}\left(\boldsymbol{\Lambda}^{m_{\Lambda}, f_{\Lambda}}\right)^{2} \times \mathbf{F}_{\mathbf{r}}^{m_{r}, f_{r}} \times \mathbf{F}_{\mathbf{s}}^{m_{s}, f_{s}}}^{\text {Family 3: Air-gap permeance + PM + Winding }}
\end{aligned}
$$

There are three main families in harmonic contents of Maxwell's air-gap magnetic pressures. The first family is due to interactions between air-gap permeance harmonics and PM magetomotrice forces harmonics. The second one is produced by interactions between air-gap permeance harmonics and stator winding magetomotrice forces harmonics. The last family is the result of interactions of three effects. 
For surface mounted PM, harmonics injected by the rotor shape, $\boldsymbol{\Lambda}_{\mathbf{k}_{\mathbf{r}}} 2 k p, 2 k f_{s}$, are negligible. By neglecting these effects, harmonic contents of the air-gap magnetic pressure, expressed by the Eq. 20 are reduced and presented in Tables IV, V and VI.

TABLE IV: Time-space harmonic contents of air-gap magnetic pressures; Family 1.

\begin{tabular}{|c|c|c|c|}
\hline $\mathrm{N}^{o}$ & $\begin{array}{l}\text { Origins of air-gap } \\
\text { pressure lines }\end{array}$ & $\begin{array}{l}\text { Spatial Order } \\
(m)\end{array}$ & $\begin{array}{l}\text { Frequency } \\
(f)\end{array}$ \\
\hline 1 & $\Lambda_{0}^{2} \mathrm{~F}_{\mathrm{r}}^{\mathrm{k} . \mathrm{k}}$ & $2 \mu p$ & $2 \mu f_{s}$ \\
\hline 2 & $\Lambda_{0}^{2} \mathrm{~F}_{\mathrm{r}}^{\mathrm{k}_{1} \cdot \mathrm{k}_{2}}$ & $\left(\mu_{2} \pm \mu_{1}\right) p$ & $\left(\mu_{2} \pm \mu_{1}\right) f_{s}$ \\
\hline 3 & $\Lambda_{\mathbf{k}_{\mathrm{s}} \cdot \mathbf{k}_{\mathrm{s}}} \mathbf{F}_{\mathrm{r}}^{\mathrm{k} \cdot \mathbf{k}}$ & $2 \mu p \pm 2 k Z_{s}$ & $2 \mu f_{s}$ \\
\hline 4 & $\Lambda_{0} \Lambda_{\mathrm{k}_{\mathrm{s}}} \mathbf{F}_{\mathrm{r}}^{\mathrm{k} \cdot \mathrm{k}}$ & $2 \mu p \pm k Z_{s}$ & $2 \mu f_{s}$ \\
\hline 5 & $\Lambda_{\mathrm{k}_{\mathrm{s}_{1}} \cdot \mathrm{k}_{\mathrm{s}_{2}}} \mathbf{F}_{\mathrm{r}}^{\mathrm{k} \cdot \mathrm{k}}$ & $2 \mu p \pm\left(k_{2} \pm k_{1}\right) Z_{s}$ & $2 \mu f_{s}$ \\
\hline 6 & $\Lambda_{0} \Lambda_{\mathrm{k}_{\mathrm{s}}} \mathbf{F}_{\mathrm{r}}^{\mathrm{k}_{1} \cdot \mathrm{k}_{2}}$ & $\left(\mu_{2} \pm \mu_{1}\right) p \pm k Z_{s}$ & $\left(\mu_{2} \pm \mu_{1}\right) f_{s}$ \\
\hline 7 & $\Lambda_{\mathbf{k}_{\mathrm{s}} \cdot \mathbf{k}_{\mathrm{s}}} \mathbf{F}_{\mathrm{r}}^{\mathrm{k}_{1} \cdot \mathrm{k}_{2}}$ & $\left(\mu_{2} \pm \mu_{1}\right) p \pm 2 k Z_{s}$ & $\left(\mu_{2} \pm \mu_{1}\right) f_{s}$ \\
\hline 8 & $\Lambda_{\mathrm{k}_{\mathrm{s}_{1}} \cdot \mathrm{k}_{\mathrm{s}_{2}}} \mathbf{F}_{\mathrm{r}}^{\mathrm{k}_{1} \cdot \mathrm{k}_{2}}$ & $\left(\mu_{2} \pm \mu_{1}\right) p \pm\left(k_{2} \pm k_{1}\right) Z_{s}$ & $\left(\mu_{2} \pm \mu_{1}\right) f_{s}$ \\
\hline
\end{tabular}

TABLE V: Time-space harmonic contents of air-gap magnetic pressures; Family 2.

\begin{tabular}{|c|c|c|c|}
\hline $\mathrm{N}^{o}$ & $\begin{array}{l}\text { Origins of air-gap } \\
\text { pressure lines }\end{array}$ & $\begin{array}{l}\text { Spatial Order } \\
(m)\end{array}$ & $\begin{array}{l}\text { Frequency } \\
(f)\end{array}$ \\
\hline 9 & 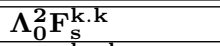 & $2 \nu p$ & $2 f_{n}^{s}$ \\
\hline 10 & $\Lambda_{0}^{2} \mathrm{~F}_{\mathrm{s}}^{\mathrm{k}_{1} \cdot \mathrm{k}_{2}}$ & $\left(\nu_{2} \pm \nu_{1}\right) p$ & $f_{n_{2}}^{s} \pm f_{n_{1}}^{s}$ \\
\hline 11 & $\Lambda_{\mathbf{k}_{\mathrm{s}} \cdot \mathbf{k}_{\mathrm{s}}} \mathbf{F}_{\mathrm{s}}^{\mathrm{k} \cdot \mathrm{k}}$ & $2 \nu p \pm 2 k Z_{s}$ & $2 f_{n}^{s}$ \\
\hline 12 & $\Lambda_{0} \Lambda_{\mathrm{k}_{\mathrm{s}}} \mathrm{F}_{\mathrm{s}}^{\mathrm{k} \cdot \mathrm{k}}$ & $2 \nu p \pm k Z_{s}$ & $2 f_{n}^{s}$ \\
\hline 13 & $\Lambda_{\mathrm{k}_{\mathrm{s}_{1}} \cdot \mathrm{k}_{\mathrm{s}_{2}}} \mathbf{F}_{\mathrm{s}}^{\mathrm{k} \cdot \mathrm{k}}$ & $2 \nu p \pm\left(k_{2} \pm k_{1}\right) Z_{s}$ & $2 f_{n}^{s}$ \\
\hline 14 & $\Lambda_{0} \Lambda_{k_{s}} F_{s}^{k_{1} \cdot k_{2}}$ & $\left(\nu_{2} \pm \nu_{1}\right) p \pm k Z_{s}$ & $f_{n_{2}}^{s} \pm f_{n_{1}}^{s}$ \\
\hline 15 & $\Lambda_{\mathrm{k}_{\mathrm{s}} \cdot \mathrm{k}_{\mathrm{s}}} \mathrm{F}_{\mathrm{s}}^{\mathrm{k}_{1} \cdot \mathrm{k}_{2}}$ & $\left(\nu_{2} \pm \nu_{1}\right) p \pm 2 k Z_{s}$ & $f_{n_{2}}^{s} \pm f_{n_{1}}^{s}$ \\
\hline 16 & $\Lambda_{\mathrm{k}_{\mathrm{s}_{1}} \cdot \mathbf{k}_{\mathrm{s}_{2}}} \mathbf{F}_{\mathrm{s}}^{\mathrm{k}_{1} \cdot \mathrm{k}_{2}}$ & $\left(\nu_{2} \pm \nu_{1}\right) p \pm\left(k_{2} \pm k_{1}\right) Z_{s}$ & $f_{n_{2}}^{s} \pm f_{n_{1}}^{s}$ \\
\hline
\end{tabular}

TABLE VI: Time-space harmonic contents of air-gap magnetic pressures; Family 3.

\begin{tabular}{|c|l|l|l|}
\hline $\mathrm{N}^{o}$ & $\begin{array}{l}\text { Origins of air-gap } \\
\text { pressure lines }\end{array}$ & $\begin{array}{l}\text { Spatial Order } \\
(m)\end{array}$ & $\begin{array}{l}\text { Frequency } \\
(f)\end{array}$ \\
\hline \hline 17 & $\boldsymbol{\Lambda}_{\mathbf{0}}^{\mathbf{2}} \mathbf{F}_{\mathbf{r}}^{\mathbf{k}} \mathbf{F}_{\mathbf{s}}^{\mathbf{k}}$ & $(\mu \pm \nu) p$ & $\mu f_{s} \pm f_{n}^{s}$ \\
\hline 18 & $\boldsymbol{\Lambda}_{\mathbf{k}_{\mathbf{s}} \cdot \mathbf{k}_{\mathbf{s}} \mathbf{F}_{\mathbf{r}}^{\mathbf{k}} \mathbf{F}_{\mathbf{s}}^{\mathbf{k}}}$ & $(\mu \pm \nu) p \pm 2 k Z_{s}$ & $\mu f_{s} \pm f_{n}^{s}$ \\
\hline 19 & $\boldsymbol{\Lambda}_{\mathbf{0}} \boldsymbol{\Lambda}_{\mathbf{k}_{\mathbf{s}}} \mathbf{F}_{\mathbf{r}}^{\mathbf{k}} \mathbf{F}_{\mathbf{s}}^{\mathbf{k}}$ & $(\mu \pm \nu) p \pm k Z_{s}$ & $\mu f_{s} \pm f_{n}^{s}$ \\
\hline 20 & $\boldsymbol{\Lambda}_{\mathbf{k}_{\mathbf{s}_{\mathbf{1}}} \cdot \mathbf{k}_{\mathbf{s}_{\mathbf{2}}} \mathbf{F}_{\mathbf{r}}^{\mathbf{k}} \mathbf{F}_{\mathbf{s}}^{\mathbf{k}}}$ & $(\mu \pm \nu) p \pm\left(k_{2} \pm k_{1}\right) Z_{s}$ & $\mu f_{s} \pm f_{n}^{s}$ \\
\hline
\end{tabular}

Three families of air-gap magnetic pressure harmonics are subdivided into 20 groups. In the formulations above, there are no saturation and static or dynamic eccentricity effects. The harmonic content of magnetic pressures can be classified by amplitude by using the following inequality:

$$
\begin{aligned}
\boldsymbol{\Lambda}_{\mathbf{k}_{\mathrm{s}}}, \boldsymbol{\Lambda}_{\mathrm{k}_{\mathrm{r}}} & \ll \boldsymbol{\Lambda}_{0} \\
\boldsymbol{\Lambda}_{\mathbf{k}_{\mathrm{r}}} & \ll \boldsymbol{\Lambda}_{\mathbf{k}_{\mathrm{s}}} \\
\mathbf{F}_{\mathbf{s}} & \ll \mathbf{F}_{\mathbf{r}}
\end{aligned}
$$

Any mechanical tool which vibrates in the air produced the noise. Magnetic vibrations are the consequences of the excitation of the mechanical system by harmonics of Maxwell's air-gap magnetic presssure $\mathbf{P}^{m, f}$ (also called electromagnetic forces). Once the time-space harmonics of magnetic pressures applied to the stator have been determined, it is necessary to perform firstly the modal analysis of the stator, and finally to determine vibrations. For the modal analysis of the mechanical struture, the analytical model described by [11], which has been successfully experimented, it is used here. This model calculate the natural frequencies $f_{m}$ and their damping $\xi_{m}$ for each mechanical deformation mode $m$. The sound power radiated by vibrations of mode $m$ at the frequency $f$ can be written as describe by [12].

\section{EXPERIMENTAL VALIDATION}

A synchronous motors with surface PM was built with the aim of validating our 'hybrid' multi-physical model. The stator and the rotor of the CWSPM-12s10p motor are presented in figure below.

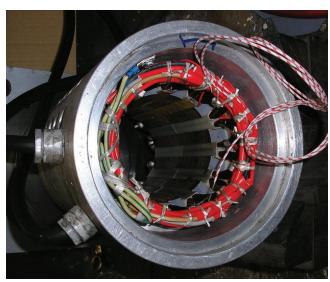

(a) $\mathrm{CW}$ stator.

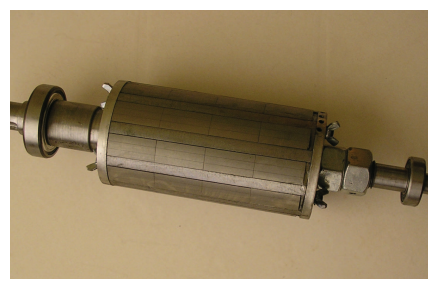

(b) SPM rotor.
Fig. 8: CWSPM-12s10p motor: stator and rotor pictures.

The input variables of the hybrid model are the operational speed $\left(N_{s}\right)$, the operational torque $\left(\Gamma_{u}\right)$, the d.c. bus voltage $\left(V_{d c}\right)$ and the strategy of modulation. In our application, it is the asynchronous modulation which was implanted. The switching frequency is $f_{c}=1000 \mathrm{~Hz}$. Figs. 9a and 9c show results of the computation of the supply voltage $V_{s}$ via our model and measurements.

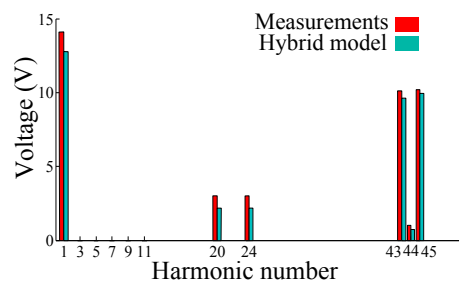

(a) SimA: voltage supply spectrum.

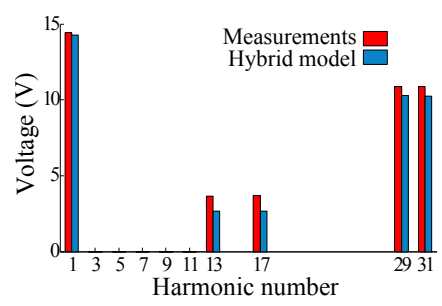

(c) SimB: voltage supply spectrum.

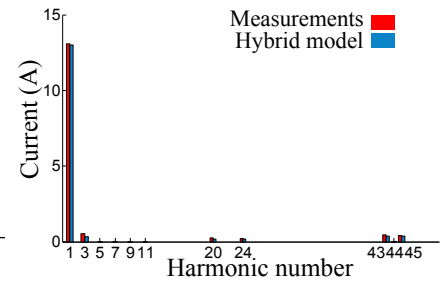

(b) SimA: Phase current spectrum.

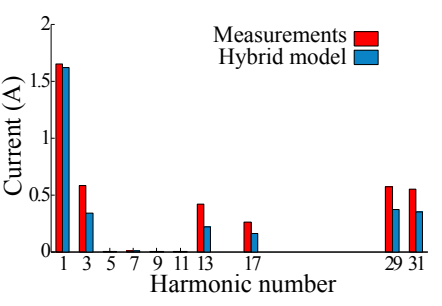

(d) SimB: Phase current spectrum.
Fig. 9: Comparison between 'hybrid' model and measurements. Electric validations.

Figs. $9 \mathrm{~b}$ and $9 \mathrm{~d}$ compare currents calculated by the hybrid model and the currents obtained from measurements. The good correspondence between these two results, allows us to assert that the calculation of the Back EMF, resistances and synchronous inductances seems to be effective for $\mathrm{CW}$ SPM topology. It is necessary to note that for all simulations, the calculation time in load or no-load case does not exceed 60 seconds. Furthermore, with previous validations of the computation of Maxwell's air-gap magnatic presssures, It is 
now possible to conclude that electric-magnetic hybrid model is accurate and fast. Main drive data of both simulations SimA and SimB are respectivetly in Tables VII and VIII.

TABLE VII: Simulation A: comparisons between measurements and 'hybrid' model results; $T_{\text {windings }}=60 \mathrm{C}$ and $T_{P M}=60 C$.

\begin{tabular}{|c|c|c|}
\hline SimA: Maximum torque & Measurements & Hybrid model \\
\hline \hline Frequency (Hz) & 45.64 & 45.41 \\
\hline D.C bus voltage (V) & 80 & 80 \\
\hline RMS voltage / fundamental (V) & $24.56 / 14.12$ & $21.98 / 12.77$ \\
\hline RMS current / fundamental (A) & $13.15 / 13.10$ & $13.03 / 13.01$ \\
\hline Power factor / cos $\varphi$ & $0.539 / 0.936$ & $0.619 / 0.923$ \\
\hline Input power (W) & 522.81 & 537.7 \\
\hline Output power (W) & 371.25 & 368.9 \\
\hline Torque (Nm) & 6.51 & 6.46 \\
\hline Efficiency (\%) & 70.9 & 68.6 \\
\hline
\end{tabular}

TABLE VIII: Simulation B: comparisons between measurements and 'hybrid' model results; $T_{\text {bobinage }}=60 \mathrm{C}$ and $T_{A P s}=60 C$.

\begin{tabular}{|c|c|c|}
\hline SimB: Flux weakening & Measurements & Hybrid model \\
\hline \hline Frequency (Hz) & 66.65 & 66.66 \\
\hline D.C bus voltage (V) & 80 & 80 \\
\hline RMS voltage / fundamental (V) & $24.89 / 14.43$ & $23.48 / 14.27$ \\
\hline RMS current / fundamental (A) & $2.21 / 1.65$ & $1.86 / 1.61$ \\
\hline Power factor / $\cos \varphi$ & $0.424 / 0.991$ & $0.581 / 0.998$ \\
\hline Input power (W) & 79.53 & 75.12 \\
\hline Output power (W) & 66.41 & 65.02 \\
\hline Torque (Nm) & 0.792 & 0.779 \\
\hline Efficiency (\%) & 83.6 & 86.5 \\
\hline
\end{tabular}

The vibratory (Figs. 10a) and acoustic (Figs. 10b) behavior of the CWSPM-12s10p motor are well modelled. In figures above, noisiest operating point (corresponding to the simulation SimA) bas been measured and simulated. The CWSPM$12 \mathrm{~s} 10 \mathrm{p}$ motor, tested at $545 \mathrm{rpm}$, is fed by an asynchronous PWM voltage supply with $f_{c}=1000 \mathrm{~Hz}$.

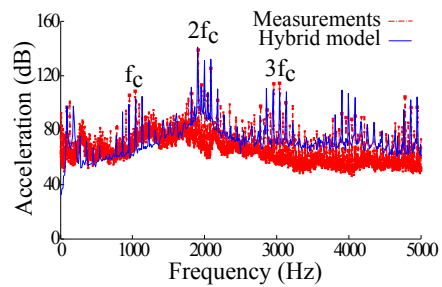

(a) SimA: Acceleration spectrum.

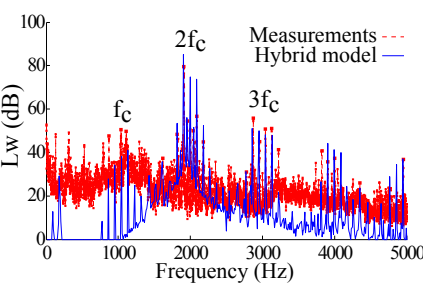

(b) SimA: Sound povel spectrum.
Fig. 10: Comparison between 'hybrid' model and measurements. Vibro-acoustic validations.

The frequencies of emerging rays are correctly estimated. Thanks to the precision in the calculation of the air-gap magnetic pressure, the precision in the prediction of the level of vibrations is improved. The calculation of the level of acoustic precision is also satisfactory (qualitatively). However, the uncertainty in the computation of the radiation coefficient is to be taken into account.

In the previous paragraph, we demonstrated that our tool is capable of calculating the sound power level radiated by PM motors. Futhermore, by operating in variable speed range, the same conclusion can be made. To establish some low-noise

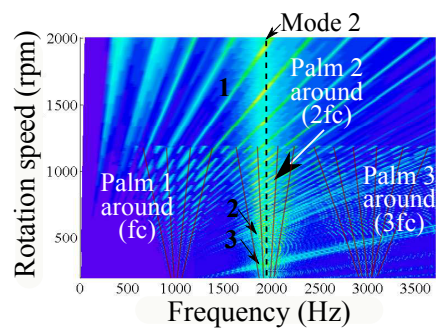

(a) 'Hybrid' model: PWM supply.

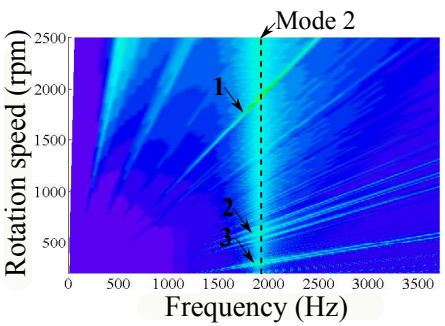

(b) 'Hybrid' model: no load.
Fig. 11: Sonogram; noise radiated by CWSPM-12s10p motor.

design rules, it would be necessary to have an overview of PM motors acoustic behavior (Figs. 11a and 11b).

The first figure represents the sonogram of the acoustic pressure radiated when the CWSPM-12s10p motor is fed by a PWM voltage. After analysis, we deduct that predominant acoustic lines (lines 1, 2, 3 and rays palms in Fig. 11a) are mainly caused by the PWM voltage supply (Family 2, $\mathbf{N}^{o} \mathbf{1 4}$ ), the PM (Family 1, $\mathbf{N}^{o} \mathbf{6}$ ) and the interaction of both effects (Family 3, $\mathbf{N}^{o} 17$ and 19). These acoustic lines resonate with the mechanical mode $m=2$.

With the objective to identify sound power lines caused only by the PM and their interaction with the stator teeth, no-load simulations without PWM voltage supply was realized (Fig. 11b). Having identified these lines (lines 1, 2, 3) as Family 1, $\mathbf{N}^{o} 6$ harmonics, it's easy to notice that in load cases with PWM voltage supply, same lines are the most acoustic energy.

\section{LOW-NOISE DESIGN RULES}

An interesting lever to reduce the noise radiated by PM motors would be to avoid resonance between harmonics of air-gap magnetic pressures, due by the PM and their interaction with stator teeth, with low rank mechanical modes. By considering the Eq. 22, the low-noise design rule is that, for a given value of $p$, the number of stator teeth $Z_{s}$ must be chosen in order to guarantee the highest value of the coefficient $m_{c r}$.

with

$$
\begin{aligned}
m_{c r}=\min \left[\left(\mu_{2} \pm \mu_{1}\right) p \pm k Z_{s}\right] \\
\mu_{1}=1,3,5,7, \ldots \\
\mu_{2}=1,3,5,7, \ldots \\
k=1,2,3,4, \ldots
\end{aligned}
$$

Once the choice of $m_{c r}$ was made, the value of the gradient $a_{c r}=\left(\mu_{2} \pm \mu_{1}\right) p$, with $f=a_{c r} f_{s}$, will have to be the lowest possible, in order to avoid resonances during low rotational speed. Table IX recapitulates low-noise design rules for a 10 poles PM rotor. $s p p$ and $k_{w 1}$ stand respectively for the number of slot per poles and per phase ans the fundamental winding coefficient.

With the aim to guarantee the electromechanic performances, the winding coefficient of the 'low-noise' topology must be consistent. In our works, a simple rule allowed us to make wise choices, for identical SPM rotor: "if $Z_{s_{c r}}<Z_{s}$, the winding coefficient of the 'low-noise' topology must be upper or equal in that of the original topology".

These criteria are applied to our motors. Results were validated by simulations, thanks to our 'hybrid' model. By 
TABLE IX: Low-noise design rule: Choice of the stator slots number for a 10 poles rotor: Family $1, \mathbf{N}^{o} \mathbf{6}, a_{c r}$ calculated for $k=1$.

\begin{tabular}{|c||c|c|c|c|c|c|c|}
\hline$s p p$ & 0.3 & 0.4 & 0.5 & 1 & 1.5 & 2 & 2.5 \\
\hline \hline$Z_{s}$ & 9 & 12 & 15 & 30 & 45 & 60 & 75 \\
\hline$m_{c r}$ & 1 & 2 & 5 & 0 & 5 & 0 & 5 \\
\hline$a_{c r}$ & 2 & 2 & $2 / 4$ & 6 & $8 / 10$ & 12 & $14 / 16$ \\
\hline$k_{w 1}$ & 0.945 & 0.933 & 0.866 & 1 & 0.945 & 0.965 & 0.951 \\
\hline
\end{tabular}

applying the low-noise design rule establishes above, the recommended stator slots number is $Z_{s_{c r}}=15(15 \mathrm{~s} / 10 \mathrm{p})$. Indeed, for the CWSPM-12s10p motor $m_{c r}=2$, while for $15 \mathrm{~s} / 10 \mathrm{p}$ topology, $m_{c r}=5$.

For identical torque-speed characteristics, sound power levels emitted respectively by CW-SPM motor and 15s10p motor are presented in Figure 12.

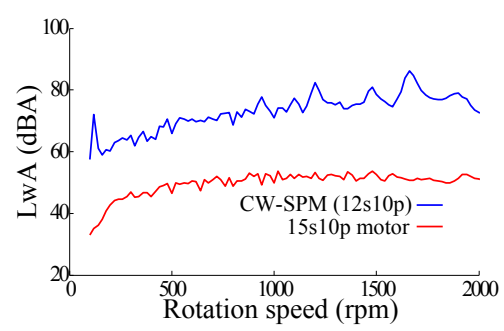

Fig. 12: Results of applications of low-noise design rule for both prototypes: sound power level.

The modulation strategy of the PWM voltage supply is identical, respectively, for CW-SPM and 15s10p motors. A significant reduction of the radiated noise is obtained by avoiding vibratory resonances of Family 1, $\mathbf{N}^{o} 6$ harmonics with low order mechanical modes (especially the machanical mode $m=2$ ).

\section{CONCLUSION}

A 'hybrid' model, analytical coupled to a FE package, of the PMSM machine, describing its electromagnetic and vibroacoustic behavior, has been etablished. The main part, the magnetic model, a numerical - analytical coupling is set up to calculate the global airgap permeances. The approach is chosen in order to take into account the wedge permeability and the rotor shape.

To demonstrate the accuracy of our 'hybrid' model, some simulated points are compared with results obtained with a fully finite element method and experiments for the acoustic part. An unequalled level of precision and speed of resolution is obtained for the computation of air-gap magnetic pressures. This model allows predicting the audible magnetic noise level radiated by the motor, and its principal resonances.

Several spectrograms or sonograms (obtained in a few minutes) are presented and compared with experiments. The model has been validated at different stages, with both experiments and Finite Element computations. This tool can be used for both designing new low-noise motors and diagnose magnetic noise issues on existing motors. A significant reduction of the radiated noise is obtained by avoiding vibratory resonances of harmonics produced by the interaction between the PM rotor and stator teeth, with low order mechanical modes.

\section{REFERENCES}

[1] P. Pellerey, and V. Lanfranchi, and G. Friedrich, Coupled Numerical Simulation Between Electromagnetic and Structural Models. Influence of the Supply Harmonics for Synchronous Machine Vibrations. IEEE Transactions on Magnetics, volume 48, pages 983-986, 2012.

[2] M. Boesing, and Rik W. De Doncker, Exploring a vibration synthesis process for the acoustic characterization of electric drives. IEEE Transactions on Industry Applications, volume 48, number 1, pages 70-78, 2012.

[3] HY. Du, and Lei Hao, and Hejie Lin, Modeling and analysis of electromagnetic vibrations in fractional slot PM machines for electric propulsion. Energy Conversion Congress and Exposition (ECCE), pages 5077-5084, 2013, IEEE.

[4] N. Bracikowski, and M. Hecquet, and P. Brochet, and S. Shirinskii, Multiphysics modeling of a permanent magnet synchronous machine by using lumped models. IEEE Transactions on Industrial Electronics, volume 59, pages 2426-2437, 2012.

[5] B. Nedjar, and S. Hlioui, and M. Lecrivain, and Y. Amara, and L. Vido, and M. Gabsi, Study of a new hybrid excitation synchronous machine. 2012 XXth International Conference on Electrical Machines (ICEM), pages 2927-2932, 2012.

[6] Nady Boules, Prediction of no-load flux density distribution in permanent magnet machines. IEEE Transactions on Industry Applications, number 3, pages 633-643, 1985.

[7] Wu, LJ and Zhu, ZQ and Staton, D and Popescu, M and Hawkins, Comparison of analytical models for predicting cogging torque in surfacemounted PM machines. IEEE, XIX International Conference on Electrical Machines (ICEM), pages 1-6, 2010.

[8] ZQ. Zhu, and David Howe, and CC. Chan, Improved analytical model for predicting the magnetic field distribution in brushless permanentmagnet machines. IEEE Transactions on Industry Applications, volume 38, number 13, pages 229-238, 2002.

[9] F. Dubas, and C. Espanet, Analytical solution of the magnetic field in permanent-magnet motors taking into account slotting effect: noload vector potential and flux density calculation. IEEE Transactions on Magnetics, volume 5, number 5, pages 2097-2109, 2009.

[10] J. Le Besnerais, and V. Lanfranchi, and M. Hecquet, and P. Brochet, Characterization and reduction of audible magnetic noise due to PWM supply in induction machines. IEEE Transactions on Industrial Electronics, volume 57, pages 1288-1295, 2010.

[11] J.F. Gieras, and C. Wang, and J.C. Lai, Noise of polyphase electric motors, 2005, CRC.

[12] Timár-P, László Timár-Peregrin and Tímár, PL, Noise and vibration of electrical machines, volume 34, 1989, North Holland.

[13] M. Fakam, and M. Hecquet, and V. Lanfranchi, and P. Brochet, and A. Randria, Electromagnetic noise comparaison between 'SPM' and 'IPM' concentrated winding synchronous machine. XV International Symposium on Electromagnetic Fields in Mechatronics, Electrical and Electronic Engineering, 2011.

[14] Damir Zarko, and Drago Ban, and Thomas A Lipo, Analytical solution for cogging torque in surface permanent-magnet motors using conformal mapping.IEEE Transactions on Magnetics, volume 44, number 1, pages $52-65,2008$.

[15] F. Scuiller, and E. Semail, and J.F. Charpentier, and others, General modeling of the windings for multi-phase ac machines. European Physical Journal- Applied Physics, volume 50, number 3, pages 15-15, 2010, Cambridge Univ Press.

[16] J. Le Besnerais, and V. Lanfranchi, and M. Hecquet, and P. Brochet, and G. Friedrich, Acoustic noise of electromagnetic origin in a fractional-slot induction machine. COMPEL: The International Journal for Computation and Mathematics in Electrical and Electronic Engineering, volume 27, number 5, pages 1033-1052, 2008, Emerald Group Publishing Limited.

[17] M. Fakam, and M. Hecquet, and V. Lanfranchi, and P. Brochet, and A. Randria, Electromagnetic noise comparaison between 'SPM' and 'IPM' concentrated winding synchronous machine. XV International Symposium on Electromagnetic Fields in Mechatronics, Electrical and Electronic Engineering, 2011.

[18] Damir Zarko, and Drago Ban, and Thomas A Lipo, Analytical solution for cogging torque in surface permanent-magnet motors using conformal mapping.IEEE Transactions on Magnetics, volume 44, number 1, pages $52-65,2008$.

[19] F. Scuiller, and E. Semail, and J.F. Charpentier, and others, General modeling of the windings for multi-phase ac machines. European Physical Journal- Applied Physics, volume 50, number 3, pages 15-15, 2010, Cambridge Univ Press. 